\title{
DISPLASIA CEMENTO-ÓSSEA FLORIDA LEVANDO À ESFOLIAÇÃO DE SEQÜESTRO ÓSSEO: RELATO DE UM CASO CLÍNICO
}

Roberta Targa STRAMANDINOLI; Andressa SEMPREBOM; Marina Oliveira RIBAS; Wilson Denis MARTINS

Será relatado um caso típico e bem definido de displasia cemento-óssea florida em mulher negra, 67 anos, com massas radiopacas envolvendo os quatro quadrantes dos maxilares. Na região posterior da mandíbula, lado direito, a lesão apresentava-se exposta à cavidade bucal, associada à osteomielite. Foi realizada remoção cirúrgica dos seqüestros ósseos para recobrimento mucoso da lesão. A análise histopatológica confirmou o diagnóstico de displasia cemento-óssea. O pós-operatório de 12 meses mostra o rebordo alveolar do lado direito com mucosa íntegra e sem nenhuma área de exposição óssea. 